\title{
I Workshop em Avancos Recentes no Preparo de Amostras
}

\author{
Faculdade de Ciências Farmacêuticas de \\ Ribeirão Preto - Universidade de São Paulo (FCFRP-USP) \\ 17 e 18 de março, 2012
}

Fernando M. Lanças ${ }^{1}$, Maria Eugênia C. Queiroz ${ }^{2}$

${ }^{1}$ Instituto de Química de São Carlos - IQSC, Universidade de São Paulo - USP

${ }^{2}$ Departamento de Química, Faculdade de Filosofia, Ciências e Letras de Ribeirão Preto - FFCLRP,

Universidade de São Paulo - USP

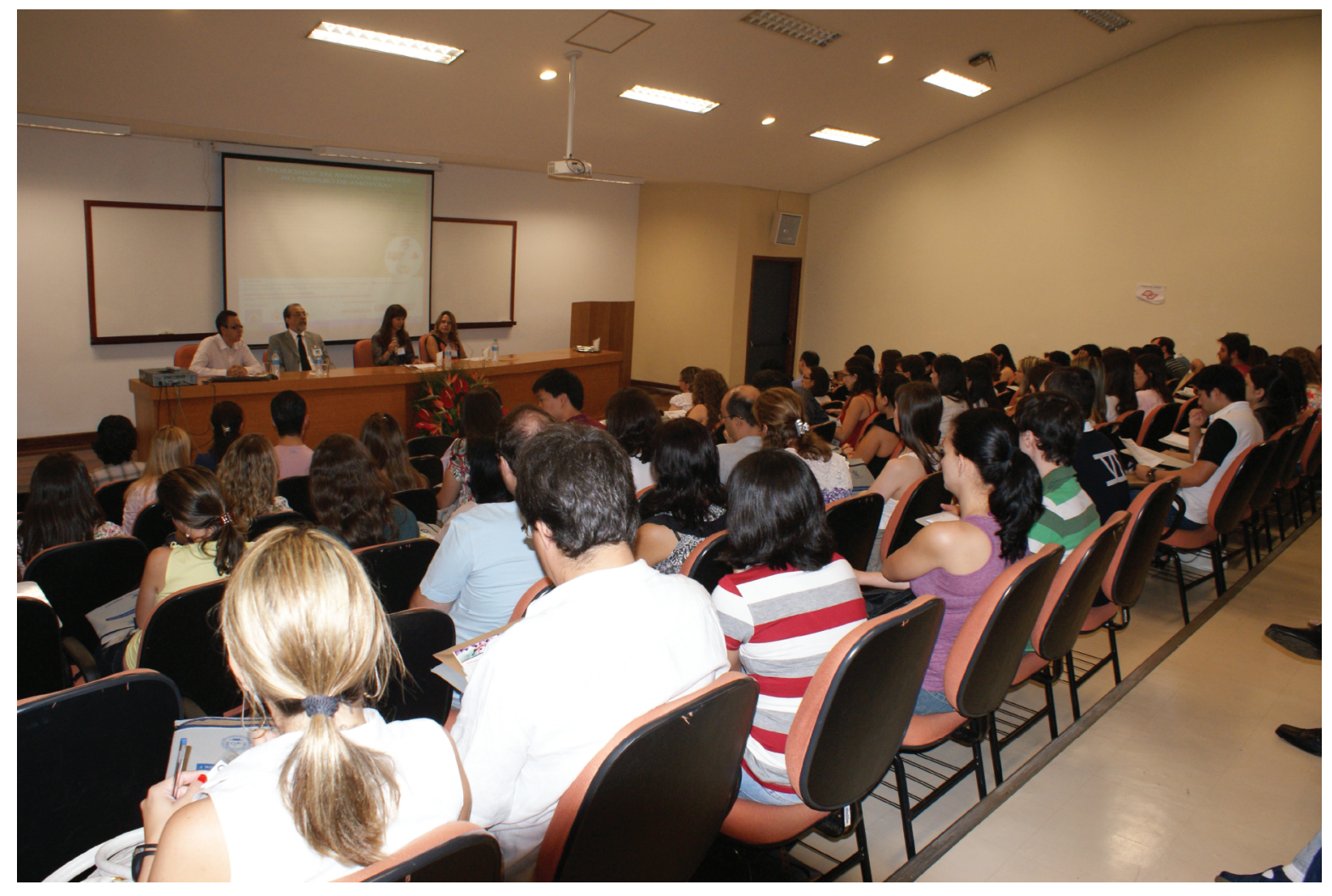




\section{Report}

Nos dias 17 e 18 de março de 2012, foi realizado na FCFRP-USP, em Ribeirão Preto, o primeiro workshop voltado exclusivamente para a discussão dos avanços recentes no preparo de amostras, com ênfase em análises orgânicas. Nesse fórum reunimos docentes, pesquisadores, discentes e pós-graduandos das unidades de ensino superior, assim como técnicos de empresas.

O workshop começou no dia 17 de março, sábado, com uma sessão solene de abertura, a qual contou com a presença da Dra. Maria Eugênia C. Queiroz da FFCLRP-USP e do Dr. Fernando M. Lanças do IQSC-USP, coordenadores do evento, da Dra. Isabel C. S. F. Jardim do IQ-UNICAMP e do Dr. Antônio C. Tedesco, Presidente da Comissão de Pós Graduação da FFCLRP (Figura 1).
Imediatamente após o encerramento da sessão de abertura, o Prof. Fernando Lanças proferiu a Palestra 1, abordando o tema Técnicas de Preparo de Amostras para Análise de Traços de Compostos Orgânicos em Matrizes Complexas: Passado, Presente e Futuro, dando início à primeira sessão de trabalhos do evento (Figura 2). Esta palestra de abertura do evento teve como principal objetivo apresentar uma revisão crítica das principais técnicas em uso para preparo de amostras complexas, nas quais o objetivo é a análise de compostos químicos presentes em quantidades muito pequenas, usualmente denominados "traços". No final da apresentação, o palestrante discutiu as principais direções que as pesquisas têm tomado neste campo, sugerindo as mais relevantes perspectivas para as diretrizes futuras nesta área. A Palestra 2 foi apresentada pela Profa. Isabel Cristina S. F. Jardim do IQ-UNICAMP sobre o tema Tendência no pre-

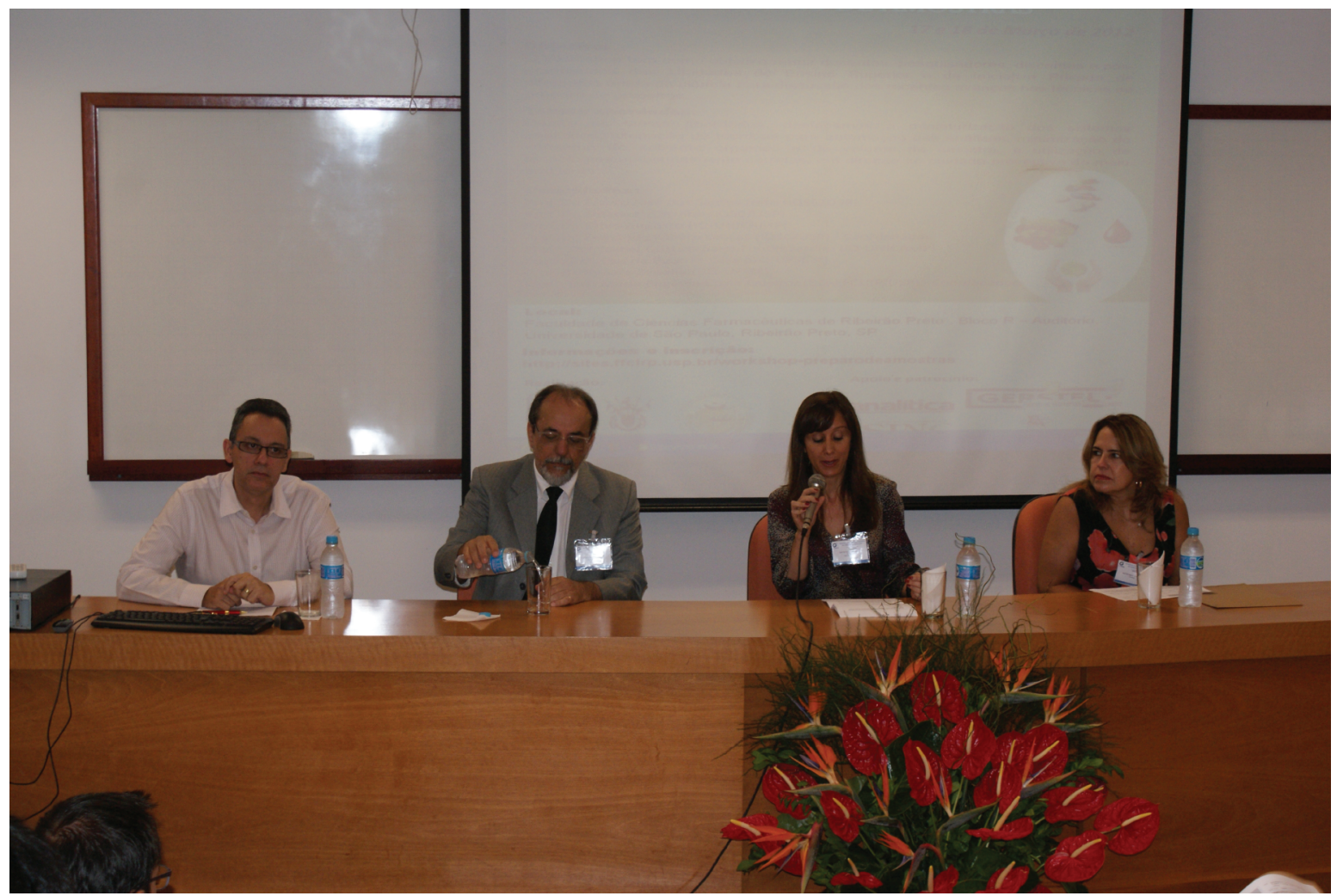

Figura 1 Dr. Antônio C. Tedesco, Dr. Fernando M. Lanças, Dra. Maria Eugênia C. Queiroz e Dra. Isabel C. S. F. Jardim. 


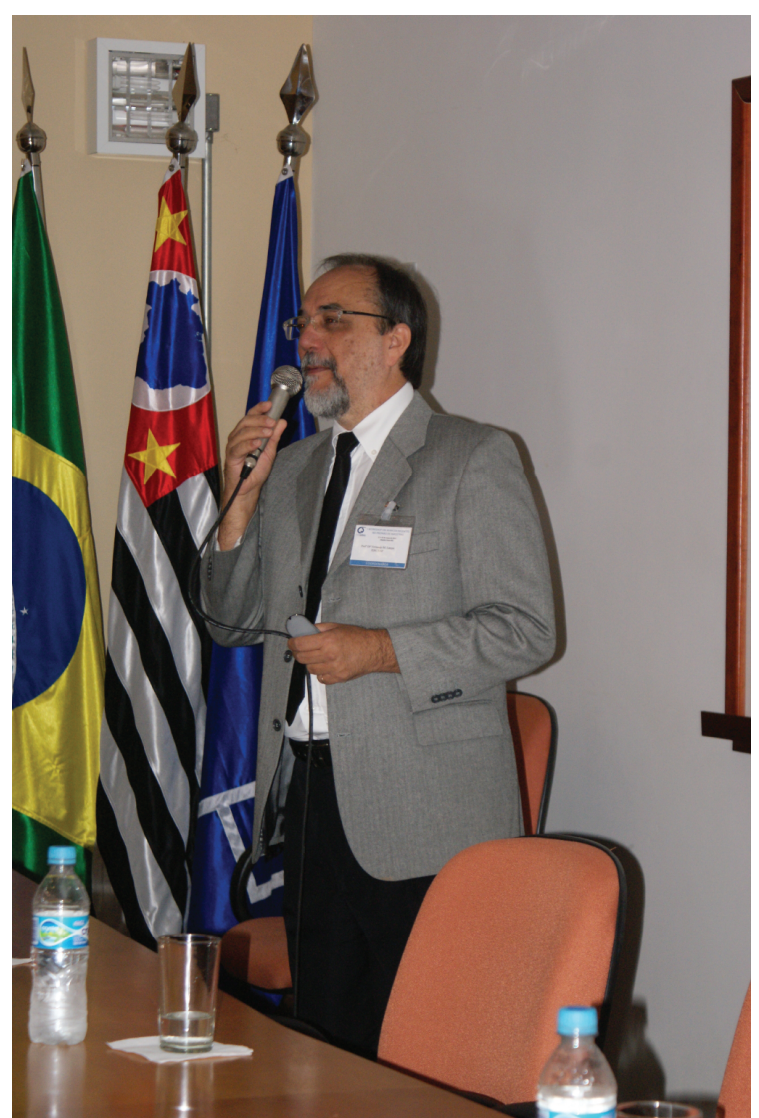

Figura 2 Dr. Fernando M. Lanças proferiu a Palestra 1, dando início à primeira sessão de trabalhos do evento.

paro de amostra na análise de resíduos no meio ambiente e em alimentos. Depois deuma discussão geral das principais técnicas empregadas nestas áreas de aplicação, a palestrante focalizou as novas tendências nestas importantes áreas, com ênfase na técnica denominada Quechers e em técnicas que empregam micro-ondas como ferramenta de auxílio no processo de extração. A última apresentação desta sessão ficou a cargo da Profa. Maria Eugênia C. Queiroz da FFCLRPUSP, com o título $O$ acoplamento da microextração em fase sólida no capilar (in-tube SPME) e cromatografia líquida para análises de fármacos em fluidos biológicos. Depois deuma discussão detalhada da importância da miniaturização das técnicas de separação e suas principais vertentes, a palestrante focalizou a apresentação em uma discussão detalhada a respeito da técnica denominada in-tube SPME, mostrando suas vantagens sobre outras técnicas miniaturizadas na análise de fármacos em fluidos biológicos.

O período da tarde do primeiro dia de workshop iniciou com a apresentação do Seminário Técnico 1, organizado pela SINC do Brasil e apresentado pelo Dra. Camila Vigna, abordando o tema SparkHolland: novo expoente em preparo de amostras. Foi discutido um produto da empresa SparkHolland desenvolvido de forma a possibilitar a integração (on-line) entre o sistema de preparo de amostras com técnicas cromatográficas de análise. A atividade seguinte da sessão foi a Palestra 4, apresentada pelo Dr. Renato Zanella, do Departamento de Química da Universidade Federal de Santa Maria (RS), cujo título foi Preparo de amostra para determinação simultânea de resíduos de pesticidas e medicamentos veterinários em alimentos de origem animal. Várias técnicas apropriadas para este enfoque foram discutidas, porém com enfoque principal na técnica Quechers, cujos resultados apresentados, obtidos no laboratório do palestrante, foram altamente estimulantes para a área. A seguir, os participantes foram convidados a participar de um coffee-break oferecido próximo ao anfiteatro (Figura 3) e auma visita à Exposição do evento organizada por empresas que atuam na área de preparo de amostras. A sessão da tarde do primeiro dia foi encerrada com mais duas apresentações: um seminário técnico promovido pela empresa Radchrom e apresentado pelo Dr. André Seo com o título Inovações no preparo de amostras: apresentação de algumas novidades disponíveis no Mercado, no qual discutiu as principais técnicas atuais de preparo de amostras para análises complexas, comercialmente disponíveis; e a Apresentação Oral 1, feita pelo Dr. Eduardo C. de Figueiredo, da Universidade Federal de Alfenas (MG). No final 


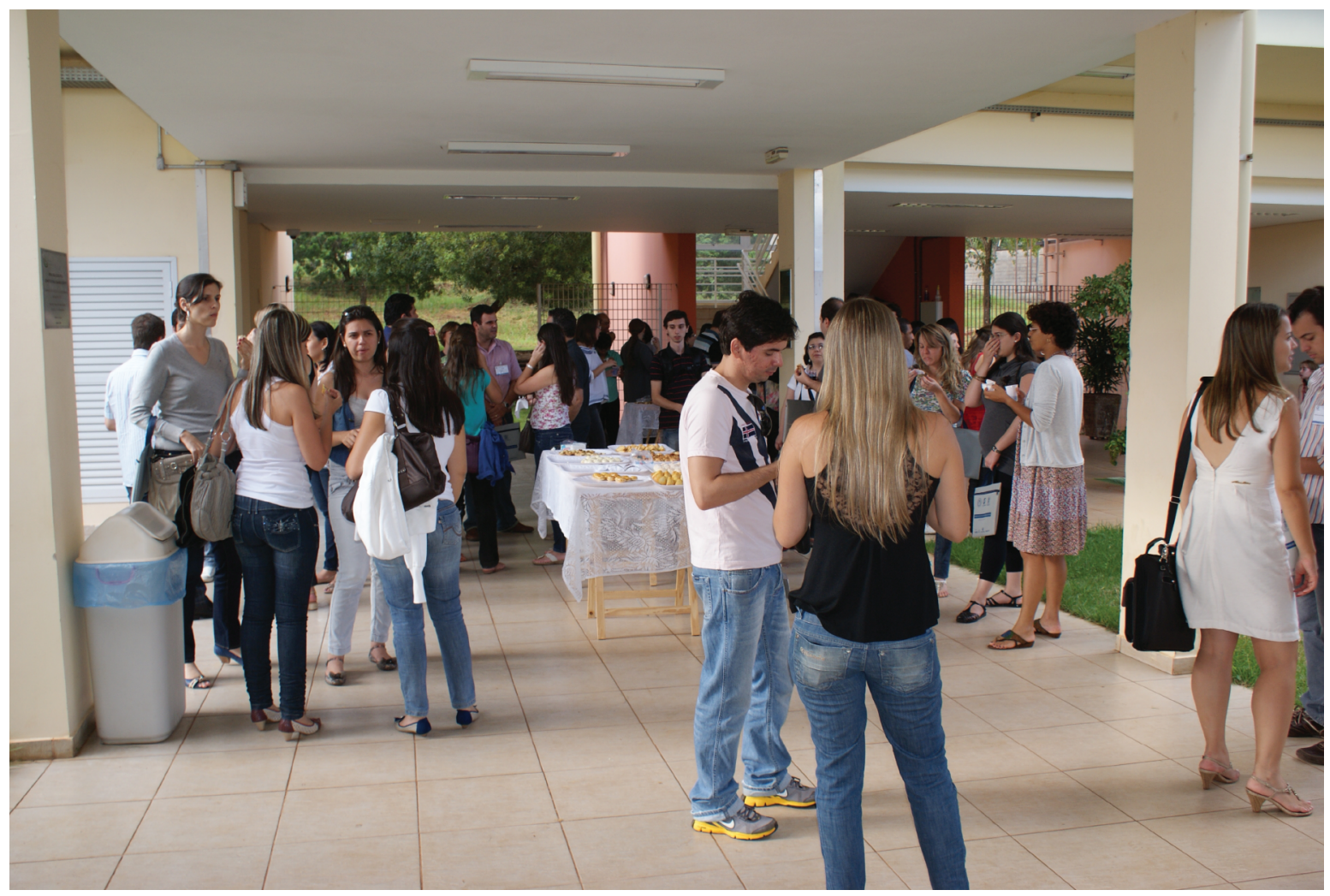

Figura 3 Coffee-break oferecido próximo ao anfiteatro.

dessa sessão, os presentes foram brindados com um coquetel de confraternização bastante animado e que permitiu o reencontro com antigos amigos e o estabelecimento de novas amizades em um ambiente descontraído e muito agradável (Figura 4).

O programa científico do segundo dia de workshop iniciou com a Palestra 5 proferida pelo Dr. Fábio Augusto do IQ-UNICAMP, com o título O acoplamento de microextração em fase sólida (SPME) e cromatografia gasosa bidimensional abrangente: aspectos instrumentais e aplicações. A apresentação enfatizou as virtudes das técnicas individuais, assim como sua conexão em linha de forma a permitir que o preparo de amostras e a separação cromatográfica - neste caso bidimensional, ou seja, empregando duas colunas de características complementares - possam ser unidas em linha para permitir uma poderosa ferramenta analítica para amostras complexas. Esta apresentação foi seguida pela Palestra 6 apresentada pelo Dr. Emanuel Carrilho do IQSC-USP, o qual explorou o tema Preparo de amostras para aplicações bioanalíticas em eletroforese capilar e microssistemas analíticos. O enfoque principal da palestra foi voltado para preparo de amostras para análises em sistemas de eletroforese capilar, assim como em microssistemas analíticos, uma área em franco desenvolvimento no presente. A última apresentação desta manhã foi a Palestra 7 da Dra. Quézia B. Cass da Universidade Federal de São Carlos (UFSCar), com o título Colunas RAM-BSA: retrospectiva e atualidades, abordando uma retrospectiva histórica do desenvolvimento deste enfoque analítico, assim como de suas vantagens e aplicações atuais. A seguir houve um intervalo para almoço, com retorno para a sessão da tarde. 


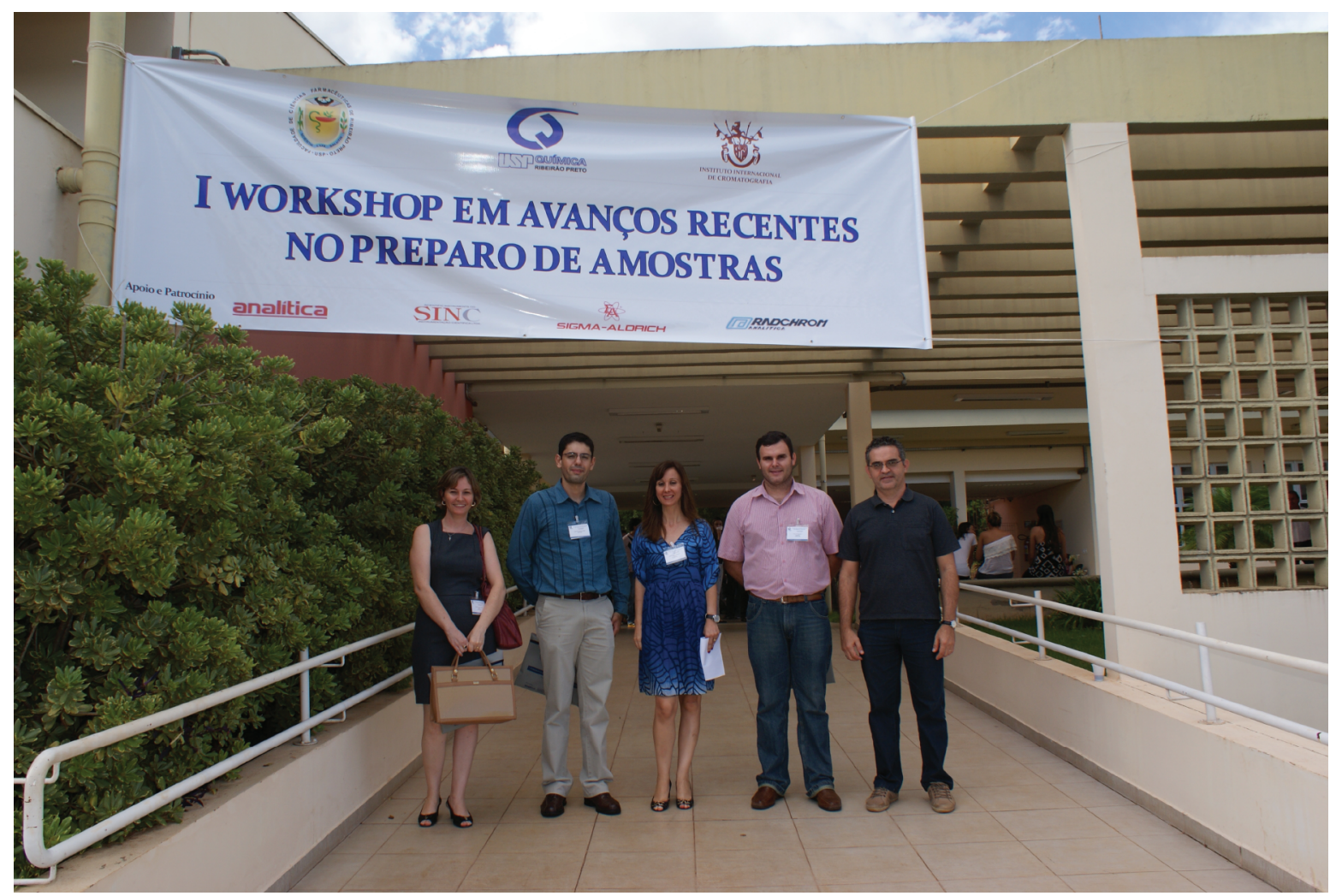

Figura 4 Dra. Cristiane M. de Gaitani, Dr. Álvaro J. S. Neto, Dra. Maria Eugênia C. Queiroz, Dr. Eduardo C. Figueiredo e Dr. Renato Zanella.

O período da tarde do segundo dia de workshop foi iniciado com o seminário técnico 3 organizado pela empresa Analítica e apresentado por Danilo Pierone e Felipe Lugão, no qualforam explorados dois temas: Sistema robótico TriplusRSH: capacidades únicas e poderosas para ampliar a produtividade e o manuseio de amostras em cromatografia e Técnicas on-line de preparo de amostras para LC-MS/MS - Aplicações em amostras ambientais e alimentos. O seminário foi seguido pela Palestra 8, proferida pelo Dr. Álvaro J. S. Neto, do IQSC-USP, na qual foi discutido o tema Acoplamento automatizado entre extração em fase sólida (SPE) e cromatografia líquida: instrumentação, aplicações e o papel da miniaturização para a química verde. Conforme proposto no próprio título da apresentação, o palestrante focalizou as vantagens em efetuar-se o acoplamento em linha entre SPE e HPLC, com ênfase em aplicações práticas, assim como discu- tiu as diversas vantagens da miniaturização das técnicas de preparo de amostra, especialmente com a atual e marcante preocupação ambiental.

Depois deuma parada para o cafezinho e visita à Exposição, a última parte do workshop iniciou com a Apresentação Oral 2, por Carlos E. D. Nazario do IQSC-USP com o tema Acoplamento on-line MIP-HPLC, no qualpartículas de polímeros impressos molecularmente (MIP) foram utilizadas para o preparo de etapa de extração seletiva, a qual foi diretamente acoplada a um sistema HPLC, permitindo a análise automatizada de amostras complexas de interesse ambiental, saúde pública e alimentos. A próxima apresentação foi realizada pela Dra. Cristiane M. de Gaitani - Apresentação Oral 3 - com o título Avaliação da microextração líquido-líquido dispersiva para análise de oxibutinina e seu metabólito em urina por eletroforese 
capilar. A apresentação tratou de uma forma bastante atual de extração (LLDME) e seu uso para o preparo de amostras de urina visando a determinação de um princípio ativo e seu principal metabólito. A última apresentação do workshop ficou a cargo do Dr. Anderson R. M. de Oliveira, o qual, na Apresentação Oral 4, abordou o tema Microextração em fase líquida empregando membranas cilíndricas ocas (HP-LPME): Fundamentos e aplicações na análise de fármacos e metabólitos. A análise de compostos de interesse farmacológico foi apresentada empregando-se como técnica de preparo de amostras a LPME que utilizamembranas cilíndricas ocas, tópico de grande interesse atual nesta área. Ao ser concluída esta apresentação, o workshop foi encerrado com uma sessão solene presidida pela Dra. Maria Eugênia C. Queiroz.

Sem qualquer dúvida, o workshop cumpriu $100 \%$ de seu objetivo original, qual seja propiciar um fórum adequado para que os interessados na área de preparo de amostras pudessem discutir seus resultados com os colegas da área. Os congressistas presentes tiveram a oportunidade de ouvir 8 Palestras proferidas por líderes brasileiros no assunto; 4 apresentações orais de pesquisadores mais jovens sobre assuntos bastante atuais; assim como 3 seminários técnicos preparados pelas empresas e que permitiram uma visão atual dos equipamentos e aplicações disponíveis comercialmente.
Pela grande procura por inscrições no workshop (as quais tiveram que ser encerradas antes do prazo pelo fato do espaço limitado), pelos comentários recebidos e pelo entusiasmo dos participantes, a Comissão Organizadora começou a discutir a realização do II Workshop, em data e local a serem divulgados oportunamente.

\section{Agradecimentos}

A Comissão Organizadora do evento agradece a todos os participantes; aos convidados palestrantes; à FFCLRP-USP, FCFRP-USP, IQSC-USP e IIC o apoio logístico na montagem e realização do evento; às empresas Analítica, SINC, Radchrom e Sigma Aldrich o Patrocínio; e aos participantes do Comitê Local que muito contribuíram para a realização do evento.

\section{Apoio e Patrocínio}

\section{analítica}
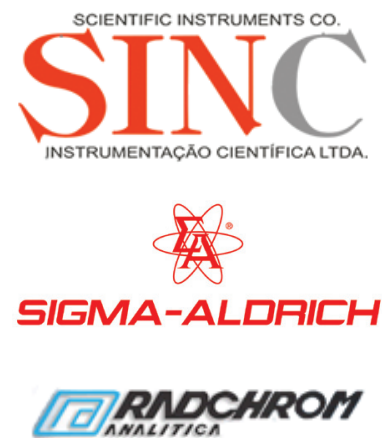